\title{
Otimização de UMA estação de tRatamento de efLUentes DE UMA INDÚSTRIA DE EMBALAGENS DE PAPEL
}

\author{
OPTIMIZATION OF A CARDBOARD PAPER FACTORY WASTEWATER \\ TREATMENT PLANT
}

\begin{abstract}
LADEMIR LUIZ BEAL
Doutor em Recursos Hídricos e Saneamento Ambiental pelo Instituto de Pesquisas Hidráulicas da Universidade Federal do Rio Grande do Sul (IPH/UFRGS). Pesquisador do Instituto de Saneamento Ambiental da Universidade de

Caxias do Sul (ISAM/UCS)
\end{abstract}

\section{LUIZ OLINTO MoNTEGGIA}

Doutor em Engenharia Ambiental pela University of New Castle upon Tyne. Professor Adjunto e Pesquisador do Instituto de Pesquisas Hidráulicas da Universidade Federal do Rio Grande do Sul (IPH/UFRGS)

\section{SaUlo VARELA Della GiUstina}

Estudante de graduação em Engenharia Ambiental da Universidade de Caxias do Sul (UCS)

Trabalho premiado $23^{\circ}$ Congresso Brasileiro de Engenharia Sanitária e Ambiental

Prêmio ABES/CETREL

\section{RESUMO}

Este trabalho versa sobre a utilização de uma estratégia de otimização de uma estação de tratamento de efluentes de uma indústria de embalagens de papel, com problemas de "foaming". Os resultados do diagnóstico inicial mostraram que o tratamento primário alcançou uma eficiência superior a $70 \%$ na remoção de sólidos suspensos. As modificaçôes operacionais realizadas foram limpezas das caixas de gordura, redução da geração de óleos e graxas nos pontos de geração. As modificações no processo na ETE foram à implementação da equalização da vazão de alimentação do tanque de aeração, adição de hipoclorito de sódio na entrada do sedimentador secundário, adição de ácido fosfórico para equilibrar a relação entre nutrientes e $\mathrm{DBO}_{5}$ e a manutenção de uma concentração e idade do lodo constante durante o processo.

PALAVRAS-CHAVE: Otimização de processos, Lodos ativados, Controle de "Foaming", efluente industrial.

\begin{abstract}
This paper describes the strategies used to optimize a cardboard paper factory wastewater treatment plant regarding operational problems caused by the occurrence of foaming and filamentous organisms. The operational modifications involved the use of an equalization tank, the reduction of oil and grease from the industrial process, the addition of sodium hypochlorite at the inlet of the secondary settler to control filamentous organisms and phosphoric acid to correct the nutrients balance and BOD. $A$ correct value of biomass concentration and sludge age were maintained constant all the time. The first results showed that the TSS removal efficiency in the primary settler was higher than $70 \%$, followed by an improved performance of the biological reactor due to the control of flamentous organisms and better performance of the secondary settler.
\end{abstract}

KEYWORDS: Process optimization; activated sludge; foaming control; industrial wastewater.

\section{INTRODUÇÃO}

O sistema de tratamento de efluente de uma indústria de embalagens de papel, objeto deste estudo tem um processo que contempla desde o tratamento primário até tratamento terciário. O fluxograma do processo é apresentado na Figura 1.

O efluente industrial, por apresentar concentrações de SS, DQO e $\mathrm{DBO}_{5}$ elevadas passa por um tratamento primário e após é misturado ao efluente gerado nos refeitório e sanitários. Desta forma, este segundo efluente confere uma parcela da necessidade de nutrientes para o sistema de lodos ativados.

\section{Microrganismos flamentosos}

O processo de lodos ativados pode ser suscetível a um crescimento descontrolado de microrganismos filamentosos que poderão ocasionar dois tipos de fenômenos que prejudicam a performance do sistema de lodos ativados bem como a sedimentação deste lodo biológico no sedimentador secundário que são o "bulking" e o "foaming". Tchobanoglous et al (2003), listam diversas causas do surgimento desses fenômenos tais como: variações na vazão de alimentação, variaçôes na composição, pH, temperatura, septicidade, balanço de nutrientes, natureza dos componentes do efluente, suprimento limitado de oxigênio, mistura insuficiente, curto circuito, projeto do 


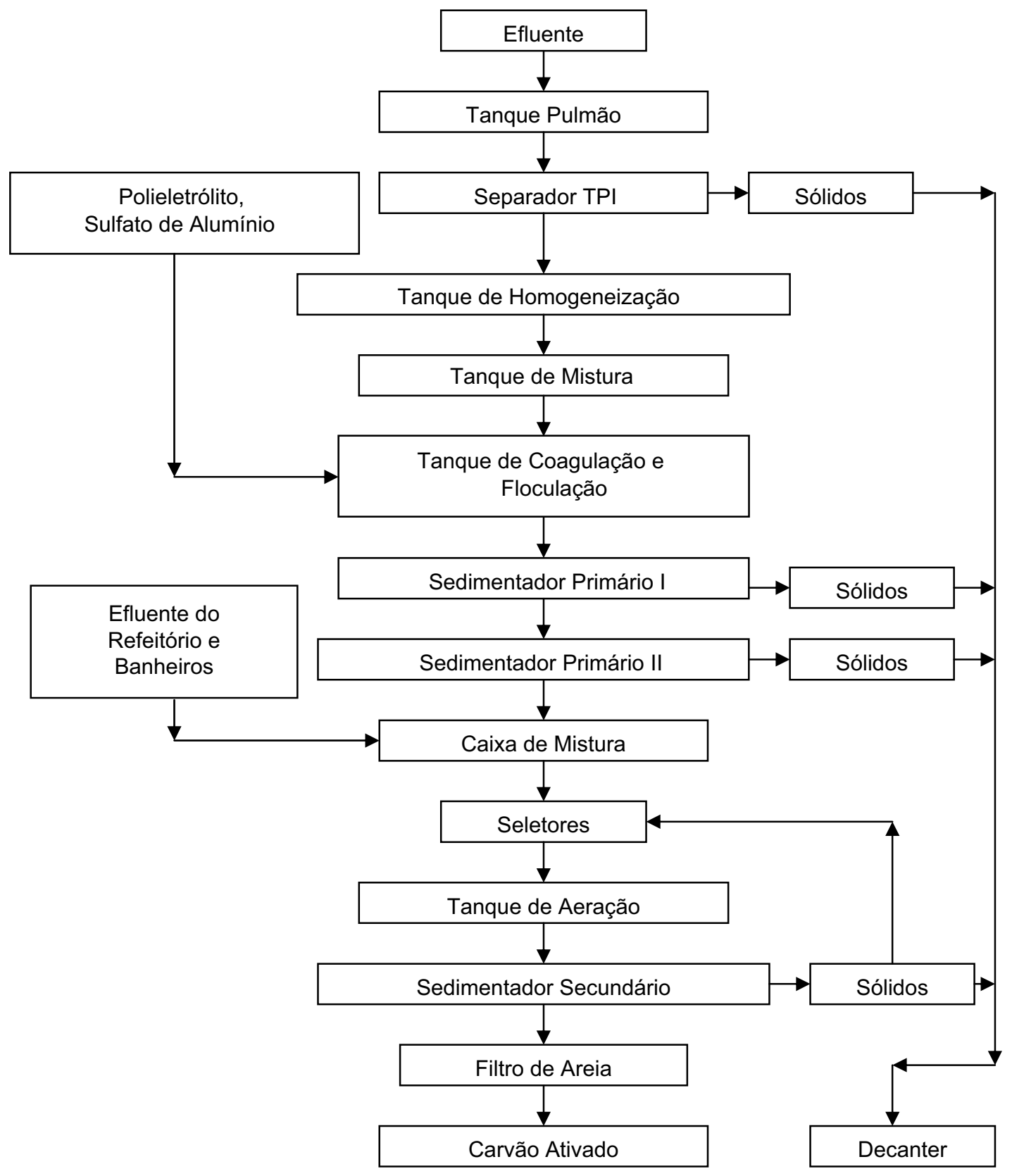

Figura I- Fluxograma da estação de tratamento de efluente

sedimentador secundário, capacidade limitada do reciclo de lodo, baixa concentração de oxigênio dissolvido, baixo $\mathrm{A} / \mathrm{M}$ e $\mathrm{DBO}_{5}$ solúvel insuficiente.

Apesar de todos os fatores listados acima, pode, em alguns casos outros elementos interferirem. Thompson e Forster (2003), registraram que provavelmente o boro presente na elaboração de adesivo de papel corrugado pode ter influenciado no surgimento do fenômeno de "bulking" em um sistema de lodos ativados de uma fábrica de papel.
Já Pernelle et al (2000) afirmam que o surgimento de microrganismos filamentosos deve-se a uma soma de diversos fatores. Somente uma variação na carga orgânica afluente ou uma deficiência de oxigênio dissolvido não é condição suficiente, porém a existência dos dois fatores conjuntamente irá favorecer este fenômeno. Jenkins et al (1993), cita que a Nocardia spp. (provavelmente o microrganismo existente) se estabelece de forma oportunista quando alguns dos seguintes aspectos são contemplados:
1. Presença de sulfetos no efluente de alimentação;

2. Presença de Óleos e Graxas em efluente doméstico favorecendo o surgimento do "foaming";

3. Desequilíbrio ou ausência de nutrientes;

4. Baixa ou nula concentração de oxigênio;

5. Cargas orgânicas variáveis e

6. Vazôes de alimentação variável.

No caso específico da estação de tratamento de efluente deste artigo, foi 
constatada presença de $\mathrm{O} \& \mathrm{G}$, desequilíbrio de nutrientes (as concentrações de fósforo estavam abaixo do mínimo necessário), cargas orgânicas variáveis e vazões alimentação variável.

\section{MATERIAIS E MÉTODOS}

$\mathrm{Na}$ estação de tratamento de efluentes foram realizadas quatro campanhas de amostragem, considerando oito pontos de tomada de amostras apresentados na Tabela 1 .

Além desses pontos para realização de análises de parâmetros físicos, físicoquímicos, foram realizadas amostragens nas três câmaras que compóem o tanque de aeração para estabelecer a concentração de biomassa e realizar investigação de espécies de microrganismos que compõem esta biomassa. As análises realizadas nos oito pontos foram $\mathrm{pH}$, SST, SSV, SSF, DQO, $\mathrm{DBO}_{5}$, Nitrogênio Amoniacal, Nitrogênio total, Nitrato, Nitrito e Fósforo.

Os resultados das análises das amostragens realizadas nas campanhas 1,2 e 3 são provenientes das composições das amostragens realizadas. Essas amostragens foram realizadas durante um período de 24 horas de funcionamento da ETE, em intervalos de uma hora, contemplando em cada campanha um ciclo inteiro de trabalho. Em cada ponto amostrado foi calculada a vazão para assim compor a alíquota encaminhada para análise. $\mathrm{O}$ volume final de cada alíquota foi calculado utilizando a seguinte fórmula:

$\mathrm{V}_{\mathrm{f}}=\mathrm{V}_{1} \mathrm{x} \frac{\mathrm{Q}_{1}}{\mathrm{Q}_{\mathrm{T}}}+\mathrm{V}_{2} \mathrm{x} \frac{\mathrm{Q}_{2}}{\mathrm{Q}_{\mathrm{T}}}+\ldots+\mathrm{V}_{24} \mathrm{x} \frac{\mathrm{Q}_{24}}{\mathrm{Q}_{\mathrm{T}}}$

$\mathrm{V}_{\mathrm{f}}$ : Volume final encaminhado para análise em cada ponto (L);

$\mathrm{V}_{1} \ldots \mathrm{V}_{24}$ : volumes coletados no período de 24 horas em cada ponto (1L);

$\mathrm{Q}_{1} \ldots \mathrm{Q}_{24}$ : vazão durante o período de 24 horas em cada ponto $\left(\mathrm{m}^{3} / \mathrm{h}\right)$;

$\mathrm{Q}_{\mathrm{T}}$ : Vazão total no período de 24 horas $\left(\mathrm{m}^{3} / \mathrm{h}\right)$.

A quarta campanha foi realizada somente na entrada do tanque de aeração para investigar as variações de carga orgânica e nutrientes durante um período de 24 horas. Nessa campanha as amostras foram coletadas sempre que a bomba de alimentação do tanque de aeração era acionada. Os resultados das análises são provenientes da composição de amostras a cada duas horas. Assim, para esta quarta campanha trabalhou-se

Tabela I - Pontos de amostragem na ETE

\begin{tabular}{lc}
\hline Ponto & Local de amostragem \\
\hline Ponto 1 & Entrada da estação \\
Ponto 2 & Tanque de homogeneização \\
Ponto 3 & Entrada de efluente doméstico \\
Ponto 4 & Saída do sedimentador primário \\
Ponto 5 & Entrada do tanque de aeração \\
Ponto 6 & Saída do sedimentador secundário \\
Ponto 7 & Saída do filtro de areia \\
Ponto 8 & Saída do 20 filtro de carvão ativado \\
\hline
\end{tabular}

com doze dados para um mesmo ponto (ponto 5).

\section{RESULTADOS}

Os resultados da primeira campanha de monitoramento estão apresentados nas Tabelas 2,3 e 4 . o comportamento dos parâmetros durante o processo de tratamento são apresentados nas figuras subseqüientes.

\section{Comportamento de sólidos}

O comportamento dos sólidos no processo de tratamento foi condizente com o esperado, indicando que a eficiência do processo para estes parâmetros é muito boa, principalmente no tratameno primário.

A eficiência de remoção de sólidos suspensos totais (SST) nos sedimentadores primários I e II foi de 71,6\% na primeira etapa, $95,8 \%$ na segunda etapa e $96,7 \%$ na terceira campanha. Já, para SSV nos sedimentadores primários I e II a eficiência foi de 75,4\%, 96,3\% e $96,3 \%$, para a primeira, segunda e terceira campanha, respectivamente. Esta eficiência elevada também foi observada na remoção de SSF, indicando que estes estão associados aos SSV. A mesma eficiência não foi observada na sedimentação secundária.

$\mathrm{Na}$ sedimentação secundária observaram-se eficiências negativas (comparação entre a entrada do tanque de aeração e a saída do sedimentador secundário), indicando problemas com a sedimentabilidade da biomassa do tanque de aeração.

\section{Comportamento da DQO}

A eficiência de remoção de DQO no processo de tratamento foi elevada, principalmente no tratamento primário onde foram observadas eficiências de $93,8 \%, 77,7 \%$ e $80,2 \%$ na primeira, segunda e terceira campanha, respectivamente. Isso indica que a DQO está associada com as substâncias que compóem os SST, possivelmente corantes, colas e outros insumos. Já, no tratamento biológico a eficiência de remoção de DQO, além de ter sido irregular foi aquém do esperado, situando-se entre $46,9 \%$ e $73,8 \%$.

No conjunto filtro de areia mais carvão ativado a eficiência foi de $41,5 \%$, $53,1 \%$ e $81,7 \%$ na primeira, segunda e terceira campanha, respectivamente. A eficiência, nesta etapa do processo de tratamento, foi mais significativa no filtro de areia indicando uma saturação do carvão ativado.

\section{Comportamento da $\mathrm{DBO}_{5}$}

A eficiência de remoção de $\mathrm{DBO}_{5}$ no processo de tratamento tem o mesmo comportamento da DQO, ou seja, uma elevada remoção no tratamento primário. A eficiência média no tratamento primário foi de $94,2 \%, 69,5 \%$ e $61,7 \%$ para a primeira, segunda e terceira campanha, respectivamente.

Já, no processo biológico, a eficiência foi de $80,5 \%, 50,1 \%$ e $54,9 \%$ para a primeira, segunda e terceira campanha respectivamente. Essa eficiência, excetuando-se a da primeira campanha, é muito baixa para esse tipo de sistema.

\section{Análise do comportamento do processo de lodos ativados}

A análise do comportamento do processo de Lodos Ativados foi realizada utilizando-se os dados obtidos nas três primeiras campanhas e, posteriormente, 
Tabela 2 - Resultados da primeira campanha de monitoramento

\begin{tabular}{|c|c|c|c|c|c|c|c|c|}
\hline \multirow[t]{2}{*}{ Parâmetro } & \multicolumn{8}{|c|}{ Pontos de amostragens } \\
\hline & Ponto 1 & Ponto 2 & Ponto 3 & Ponto 4 & Ponto 5 & Ponto 6 & Ponto 7 & Ponto 8 \\
\hline $\mathrm{pH}$ & 8,37 & 7,67 & 6,9 & 7,15 & XXX & 7,7 & 7,75 & 7,53 \\
\hline SST (mg/L) & 2.683 & $1.017,4$ & 312,5 & 289,3 & 130 & 205 & 56 & 41,4 \\
\hline SSF $(\mathrm{mg} / \mathrm{L})$ & 500 & 87 & 41,6 & 60,7 & 10 & 27,5 & 11 & 15,6 \\
\hline $\mathrm{SSV}(\mathrm{mg} / \mathrm{L})$ & 2.183 & 930,4 & 270,8 & 228,6 & 122 & 177,5 & 45 & 25,8 \\
\hline $\mathrm{DQO}\left(\mathrm{mg} \mathrm{O}_{2} / \mathrm{L}\right)$ & 41.000 & 25.750 & 995 & 1.586 & 1.628 & 427 & 277 & 250 \\
\hline $\mathrm{DBO}_{5}\left(\mathrm{mg} \mathrm{O}_{2} / \mathrm{L}\right)$ & 22.698 & 20.741 & 619 & 1.200 & 1.420 & 277 & 126 & 172 \\
\hline N Total Kjeldahl (mg N/L) & 172 & 174,2 & 114,8 & 184,8 & 71,85 & 73 & 56 & 37 \\
\hline 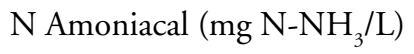 & 44,8 & 33,6 & 100,8 & 86,8 & 58,8 & 68,88 & 46,65 & 27,76 \\
\hline Nitrato $\left(\mathrm{mg} \mathrm{NO}_{3} / \mathrm{L}\right)$ & 372,91 & 359,2 & 25,5 & 11,97 & 14,71 & 15,73 & 24,97 & 20,35 \\
\hline Nitrito $\left(\mathrm{mg} \mathrm{NO}_{2} / \mathrm{L}\right)$ & 21,7 & 24,4 & 2,26 & 4,74 & 3,29 & 1,4 & 0,845 & 0,592 \\
\hline Fósforo total (mg P/L) & 5,14 & 2,57 & 16,46 & 6,66 & 1,45 & 0,58 & 0,3 & 0,4 \\
\hline
\end{tabular}

Tabela 3 - Resultados da segunda campanha de monitoramento

\begin{tabular}{|c|c|c|c|c|c|c|c|c|}
\hline \multirow[t]{2}{*}{ Parâmetro } & \multicolumn{8}{|c|}{ Pontos de amostragens } \\
\hline & Ponto 1 & Ponto 2 & Ponto 3 & Ponto 4 & Ponto 5 & Ponto 6 & Ponto 7 & Ponto 8 \\
\hline $\mathrm{pH}$ & 8,68 & 8,03 & 6,77 & 7,25 & 6,94 & 7,54 & 7,4 & 7,27 \\
\hline SST (mg/L) & $4.214,3$ & 1.910 & 460 & 81 & 508,3 & 1.780 & 510,7 & 686,4 \\
\hline $\operatorname{SSF}(\mathrm{mg} / \mathrm{L})$ & 942,9 & 290 & 146,7 & 21 & 130,5 & 200 & 128,6 & 168,2 \\
\hline $\operatorname{SSV}(\mathrm{mg} / \mathrm{L})$ & $3.271,4$ & 1.620 & 313,3 & 60 & 377,8 & 1.580 & 382,1 & 518,2 \\
\hline $\mathrm{DQO}\left(\mathrm{mg} \mathrm{O}_{2} / \mathrm{L}\right)$ & 29.600 & 18.600 & 1.184 & 4.152 & 3.222 & 1.631 & 614 & 766 \\
\hline $\mathrm{DBO}_{5}\left(\mathrm{mg} \mathrm{O}_{2} / \mathrm{L}\right)$ & 1.971 & 9.935 & 943 & 3.029 & 2.402 & 1.198 & 192 & 410 \\
\hline N Total Kjeldahl (mg N/L) & 386,4 & 103,6 & 162,4 & 75,6 & 184,8 & 184,8 & 26,88 & 61,6 \\
\hline $\mathrm{N}$ Amoniacal $\left(\mathrm{mg} \mathrm{N}-\mathrm{NH}_{3} / \mathrm{L}\right)$ & 81,2 & 70 & 117,6 & 33,6 & 81,2 & 61,6 & 26,32 & 31,36 \\
\hline Nitrato $\left(\mathrm{mg} \mathrm{NO}_{3} / \mathrm{L}\right)$ & 190,8 & 24,3 & 4,73 & 1,03 & 2,67 & 3,2 & 1,25 & 1,76 \\
\hline Nitrito $\left(\mathrm{mg} \mathrm{NO}_{2} / \mathrm{L}\right)$ & 119,7 & 6,38 & 0,914 & 0,555 & 0,708 & 0,61 & 0,65 & 0,945 \\
\hline Fósforo total (mg P/L) & 3,69 & 4,58 & 2,09 & 9,31 & 0,965 & 18,3 & 2,49 & 3,37 \\
\hline
\end{tabular}

Tabela 4 - Resultados da terceira campanha de monitoramento

\begin{tabular}{|c|c|c|c|c|c|c|c|c|}
\hline \multirow[t]{2}{*}{ Parâmetro } & \multicolumn{8}{|c|}{ Pontos de amostragens } \\
\hline & Ponto 1 & Ponto 2 & Ponto 3 & Ponto 4 & Ponto 5 & Ponto 6 & Ponto 7 & Ponto 8 \\
\hline \multicolumn{9}{|l|}{$\mathrm{pH}$} \\
\hline SST (mg/L) & 451,1 & 2575 & 256 & 86 & 144 & 349 & 42 & 73,5 \\
\hline $\operatorname{SSF}(\mathrm{mg} / \mathrm{L})$ & 46,7 & 446 & 20 & 8 & 18 & 71,4 & 12 & 6,5 \\
\hline SSV (mg/L) & 404,4 & 2129 & 236 & 78 & 126 & 277,6 & 30 & 67 \\
\hline $\mathrm{DQO}\left(\mathrm{mg} \mathrm{O}_{2} / \mathrm{L}\right)$ & 24.950 & 23.200 & 1.339 & 4.582 & 2.910 & 1.545 & 300 & 283 \\
\hline $\mathrm{DBO}_{5}\left(\mathrm{mg} \mathrm{O}_{2} / \mathrm{L}\right)$ & 6.637 & 6.610 & 778 & 2.529 & 1.684 & 760 & 175 & 139 \\
\hline N Total Kjeldahl (mg N/L) & 296,8 & 173,6 & 91,8 & 123,2 & 61,6 & 36,4 & 15,68 & 39,2 \\
\hline $\mathrm{N}$ Amoniacal $\left(\mathrm{mg} \mathrm{N}-\mathrm{NH}_{3} / \mathrm{L}\right)$ & 53,2 & 47,6 & 109,2 & 44,8 & - & 39,2 & 13,44 & 10,36 \\
\hline Nitrato $\left(\mathrm{mg} \mathrm{NO}_{3} / \mathrm{L}\right)$ & 188,3 & 68,7 & 0,784 & 0,671 & 1,08 & 0,411 & 9,97 & 9,92 \\
\hline Nitrito $\left(\mathrm{mg} \mathrm{NO}_{2} / \mathrm{L}\right)$ & 95 & 31 & 0,33 & 0,57 & 0,61 & 0,26 & 0,12 & 0,13 \\
\hline Fósforo total (mg P/L) & 2,01 & 1,05 & 11,01 & 1,29 & 8,2 & 1,45 & 0,33 & 0,4 \\
\hline
\end{tabular}


realizando uma campanha somente no ponto 5 (entrada do tanque de aeração) para verificar a característica do afluente ao tanque de aeração, sua variabilidade e conseqüentes efeitos sobre a operação deste processo. Na tabela 5 são apresentados os resultados desta campanha. Os resultados são frutos de análise de amostras compostas a cada duas horas durante um período de 24 horas.

A $\mathrm{DBO}_{5}$ na entrada do tanque de aeração variou consideravelmente durante o período de 24 horas, tendo como conseqüência uma variação na carga orgânica como apresentado a seguir na Figura 2.

As vazões afluentes ao tanque de aeração, no período de 24 horas, foram bem díspares quanto aos valores apresentados, como se pode verificar na Figura 2. Este comportamento influencia diretamente a carga orgânica aplicada ao sistema de lodos ativados. Em testes de correlação realizados, foi constatada uma maior correlação $(0,982)$ entre vazão e carga orgânica do que carga orgânica e $\mathrm{DBO}_{5}(0,68)$, corroborando a afirmativa acima.

A Figura 3 apresenta a carga orgânica afluente e na linha horizontal a carga orgânica equalizada. Esta carga orgânica foi calculada após o cálculo da vazão equalizada e do dimensionamento de um tanque de equalização.

A oscilação da carga orgânica aplicada influencia na concentração de oxigênio dissolvido no tanque de aeração além de contribuir para o surgimento de microrganismos filamentosos.

\section{Nutrientes no tanque de aeração}

Os principais nutrientes em um sistema de lodos ativados são Nitrogênio e Fósforo. A relação entre a matéria orgânica (expressa como $\mathrm{DBO}_{5}$ ) e esses nutrientes $\left(\mathrm{DBO}_{5}: \mathrm{N}: \mathrm{P}\right)$ é 100:5:1. A importância da observação desse balanço no processo é devido à função dos nutrientes no metabolismo e na estruturação do tecido celular na reprodução dos microrganismos. A relação entre $\mathrm{DBO}_{5}$ e Nitrogênio, observada durante as quatro campanhas, foi satisfatória, porém a relação entre $\mathrm{DBO}_{5}$ e Fósforo foi muito alta indicando uma clara deficiência deste nutriente. A Tabela 6 apresenta os resultados das três campanhas e a Figura 5 apresenta o comportamento durante o perfil de 24 horas na entrada da estação.
Tabela 5 - Perfil de monitoramento 24 horas no ponto 5

\begin{tabular}{ccccc}
\hline Amostra & $\mathrm{DQO}$ & $\mathrm{DBO}_{5}$ & Fósforo total & N Total \\
\hline 1 & 2.750 & 2.024 & 5,87 & 128,8 \\
3 & 3.145 & 2.315 & 2,9 & 123,2 \\
5 & 2.300 & 1.693 & 6,35 & 112 \\
7 & 2.255 & 1.660 & 5,79 & 134,4 \\
9 & 940 & 692 & 14,79 & 145,6 \\
11 & 1.765 & 1.299 & 9,32 & 134,4 \\
13 & 2.090 & 1.538 & 6,75 & 145,6 \\
15 & 2.830 & 2.083 & 3,94 & 156,8 \\
17 & 2.915 & 2.145 & 4,02 & 112 \\
19 & 2.915 & 2.145 & 4,66 & 151,2 \\
21 & 2.405 & 1.770 & 5,95 & 140 \\
23 & 2.280 & 1.678 & 8,6 & 179,2 \\
\hline
\end{tabular}
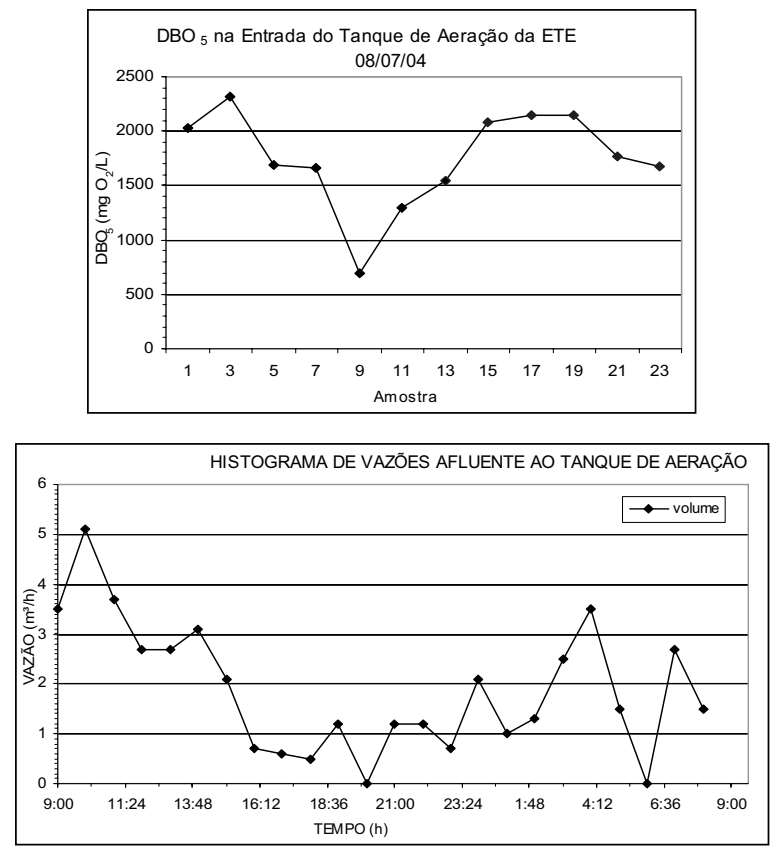

Figura 2 - Variação da $\mathrm{DBO}_{5}$ na entrada do tanque de aeração e histograma de vazões

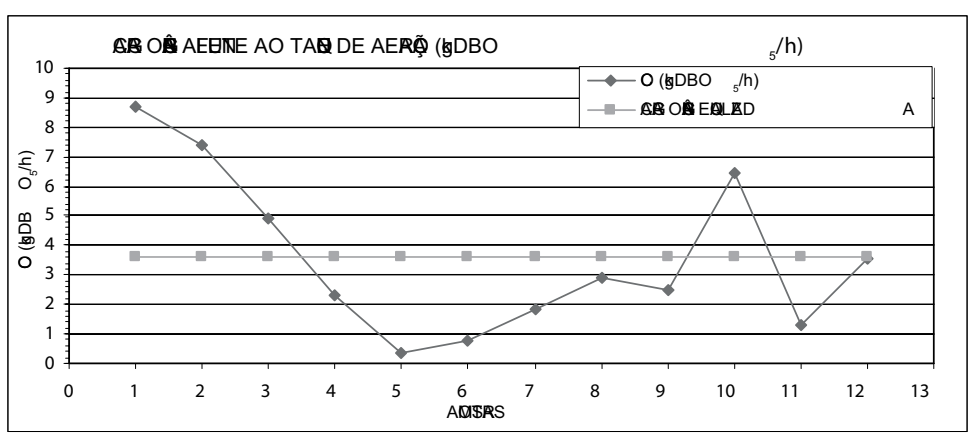

Figura 3 - Carga orgânica afluente ao tanque de aeração 
Tabela 6 - Resultados da relação $\mathrm{DBO}_{5}: \mathrm{N}: \mathrm{P}$

\begin{tabular}{cccccccc}
\hline Campanha & & \multicolumn{2}{c}{$\begin{array}{c}\text { Concentração } \\
(\mathrm{mg} / \mathrm{L})\end{array}$} & \multicolumn{2}{c}{$\begin{array}{c}\text { Relaçăo } \\
\text { observada }\end{array}$} & \multicolumn{2}{c}{$\begin{array}{c}\text { Concentração } \\
\text { necesária }\end{array}$} \\
& $\mathrm{DBO}_{5}^{*}$ & $\mathrm{~N}_{\mathrm{T}}$ & $\mathrm{P}_{\mathrm{T}}$ & $\mathrm{DBO}_{5}: \mathrm{N}_{\mathrm{T}}$ & $\mathrm{DBO}_{5}: \mathrm{P}_{\mathrm{T}}$ & $\mathrm{N}_{\mathrm{T}}$ & $\mathrm{P}_{\mathrm{T}}$ \\
\hline 1 & 1.420 & 71,8 & 1,45 & $98,8: 5$ & $979,3: 1$ & 71,0 & 14,20 \\
2 & 2.402 & 184,8 & 0,96 & $65: 5$ & $2.489: 1$ & 120,1 & 24,02 \\
3 & 1.684 & 61,6 & 8,2 & $136,7: 5$ & $205,4: 1$ & 84,2 & 16,84 \\
\hline
\end{tabular}

* $\mathrm{DBO}_{5} \mathrm{em} \mathrm{mg} \mathrm{O} / \mathrm{L}$

Na Figura 4 observa-se o comportamento das concentrações de $\mathrm{Ni}$ trogênio Total Kjedhal ao longo de um período de 24 horas. A concentração de nitrogênio no efluente é suficiente para que a relação $\mathrm{DBO}_{5}: \mathrm{N}$ seja satisfeita, ou seja, não há necessidade de adição de nitrogênio amoniacal, utilizando uma fonte externa. Já, quanto ao fósforo, há a necessidade de adicionar complemento, como revelam os dados apresentados.

\section{Análise da biomassa e microbiológica do tanque de aeração}

A análise da biomassa do tanque de aeração revelou uma oscilação muito grande da concentração de SSV e um elevado teor de lodo. As concentraçōes de SSV nas etapas estudadas estão listadas na Tabela 7 .

$\mathrm{O}$ teor de lodo nas etapas estudadas, variou de $950 \mathrm{~mL} / \mathrm{L}$ a $980 \mathrm{~mL} / \mathrm{L}$. Para calcular os valores de A/M foram considerados uma vazão de $45 \mathrm{~m}^{3} /$ dia, volume do tanque de aeração de $100 \mathrm{~m}^{3} \mathrm{e}$ os resultados de $\mathrm{DBO}_{5}$ aqueles obtidos nas campanhas efetuadas. Os valores de A/M nessas etapas foram de 0,063, 0,238 e 0,244 para a primeira etapa, $0,12,0,183$ e 0,0893 para a segunda etapa e de 0,137 e 0,135 para a quarta etapa. Esses valores, quando analisados dessa forma estão fora do previsto em projeto $(0,06)$, com exceção do primeiro valor, mas estão na faixa do processo de aeração prolongada, pretendido pelo projeto original. Porém, devido à variabilidade desses resultados, juntamente com os valores de IVL, não há uma homogeneidade de controle dos parâmetros operacionais.

Relativamente às análises de biomassa, via observação microscópica, foram detectados microrganismos filamentosos, alguns protozoários e baixa diversidade de formação.
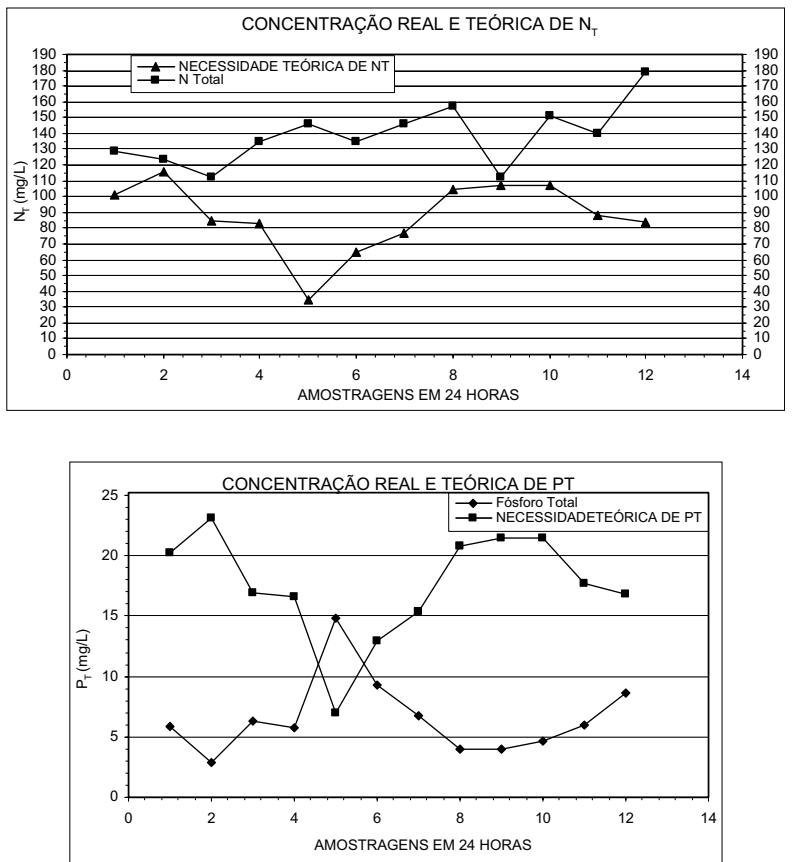

Figura 4 - Concentração real e teórica de $\mathbf{N}_{T}$

Tabela 7- Concentrações de SSV no tanque de aeração

\begin{tabular}{cccc}
\hline Etapa & Ponto 9 & Ponto 10 & Ponto 11 \\
\hline 1 & 10.100 & 2.682 & 2.618 \\
2 & 8.960 & 5.920 & 12.100 \\
4 & 6.250 & 6.370 & \\
\hline
\end{tabular}

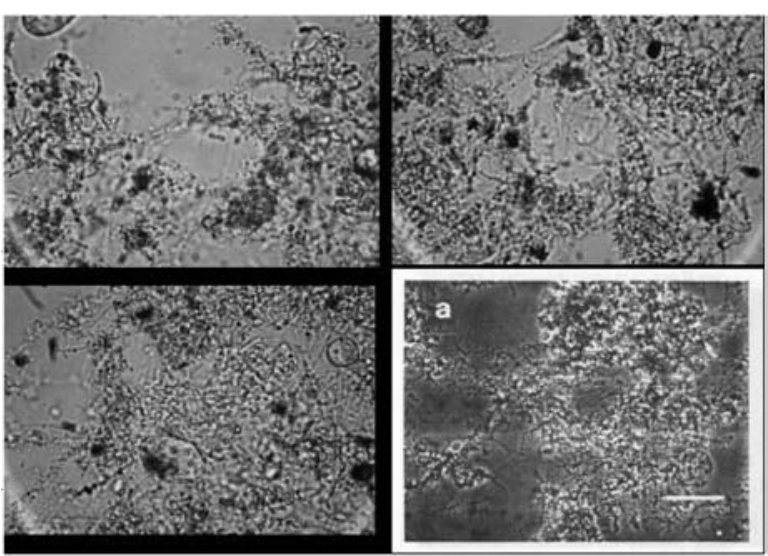

Figura 5 - Imagens de observação microscópica 
A imagem do canto inferior direito foi considerada como referência para efetuar comparações (Jenkins et al, 2004)

\section{CONCLUSÕES}

As estratégias utilizadas para que fosse possível a reversão deste quadro foi a utilização de cloração na entrada do sedimentador secundário até não haver mais detecção de microrganismos filamentosos, equalização da vazão afluente ao tanque de aeração e adição de ácido fosfórico para que houvesse um equilíbrio de nutrientes. Após 30 dias de aplicação de hipoclorito de sódio este foi retirado e não foi observado um acréscimo de microrganismos filamentosos durante as observações. A concentração utilizada foi de $3 \mathrm{mg}$ de cloro/g SSV. Cabe ressaltar que neste período a concentração de biomassa no tanque de aeração oscilou muito e a retirada de excesso de lodo foi suspensa. Concomitantemente, houve um programa diminuição de geração de $\mathrm{O} \& \mathrm{G}$ na planta industrial e uma limpeza mais freqüente das caixas de gordura. Estas estratégias têm-se mostrado eficientes e depois de 20 dias sem cloração a biomasssa atingiu valores médios de $3.840 \mathrm{mg} / \mathrm{L}$ dentro do tanque de aeração. Atualmente está sendo implementado um programa de redução de sabões e detergentes, os quais são responsáveis por uma concentração de $85 \mathrm{~g} / \mathrm{m}^{3}$ de efluente. O objetivo final é a reutilização da totalidade do efluente tratado.

\section{REFERÊNCIAS}

BELANCHE, L., et al. Prediction of the Bulking Phenomenon in Wastewater Treatment Plants. Artificial Intelligence in Engineering. V.14, p. 307-317. 2000.

HAANDEL, A., MARAIS, G. O comportamento do Sistema de Lodo Ativado. Teoria e Aplicaçôes para Projetos e Operaçãa. Universidade Federal da Paraíba. 488 p. 1999.

JENKINS, D., RICHARD, M. G., DAIGGER, G. T. Manual on the Causes and Control of Activated Sludge Bulking and Foaming. $3^{\mathrm{a}}$ Ediçāo. Lewis Publishers. 190 p. 2004.

MADONI, P., DAVOLI, D. Testing the Control of Filamentous Microorganisms Responsible for Foaming in a Full-scale Activated-Sludge Plant Running With Initial Aerobic or Anoxic Zones. Bioresource Technology. V.60, p. 43-49. 1997.

MADONI, P., DAVOLI, D. E GIBIN G. Survey of Filamentous Microorganisms from Bulking and Foaming Activated-Sludge Plants in Italy. Water Research. V.34, n.6, p. 1767-1772. 2000.

MARTINS, A. M. P. et al. Filamentous Bulking Sludge. A Critical Review. Water Research. V. 38. p. 793-817 2004.

PERNELLE, J. J., et al. Influence of Transient Substrate Overloads on the Proliferation of Filamentous Bacterial Populations in Activated Sludge Pilot Plant. Water Research, V. 35, n. 1, p. 129134. 2001.
SOBRINHO, P. A. Estudo dos fatores que influem no desempenho do processo de lodos ativados - determinação de parâmetros de projeto para esgotos predominantemente domésticos. Revista DAE.. n. 132. p. $49-85.1983$.

SODELL, J. A., SEVIOUR, R. J. Relationship Between Temperature and Growth of Organisms Causing Nocardia Foams in Ativated Sludge Plants. Water Research, V.29, n.6, p. 1555-1558. 1995.

TCHOBANOGLOUS, G., BURTON, F. L., STENSEL, H. D. Wastewater Engineering: Treatment and Reuse. 3a Ediçāo. McGraw-Hill. New York. 1.819 p. 2003

THOMPSON, G., FORSTER, C. Bulking in Activated Sludge Plants Treating Paper Mill Wastewaters. Water Research, V.37, p. 26362644. 2003.

Endereço para correspondência:

Lademir Luiz Beal

Universidade de Caxias do Sul

Rua Francisco Getúlio Vargas, I I 30

95070-560 Caxias do Sul - RS -

Brasil

Tel.: (54) 32 I 8-2 I00

Tel.: E-mail: Ilbeal@ucs.br 